\title{
Research and Simulation of the effect on distributed network protection with distribution generation
}

\author{
Zhaohui Wang ${ }^{1, ~ a, ~ H a i p e n g ~} \mathrm{Nan}^{2,}{ }^{\text {*b }}$ and Bohao Feng ${ }^{2, \mathrm{c}}$ \\ ${ }^{1}$ Xi'an University of Technology, XI'AN 710048, China; \\ ${ }^{2}$ Xi'an University of Technology, XI'AN 710048, China. \\ a346831447@qq.com, ${ }^{b}$ hxnhp@163.com, '13488140103@163.com
}

Keywords: distributed generation, distribution network, current protection.

\begin{abstract}
According to the classification and characteristics of the distributed generation, analyzes its influence on current protection for distribution network. Using the actual power grid data in MATLAB/SIMULINK to build the model, and confirmed that distributed power distribution network access will cause protection misoperation, reduce the sensitivity, unable to identify the malfunction, the influence of provide the basis for distributed power grid analysis, has strong practicability.
\end{abstract}

\section{Introduction}

In recent decades, due to the shortage of primary energy, all countries in the world are accelerating the development and utilization of renewable energy resources. Distributed generation (DG) is a high efficiency and reliable power supply system which is about 50MW - 10KW and arranged in the distribution network, DG also has other advantages, such as installed in user sides, small module and so on .However, the access of DG also has some impact on the distribution network, the traditional distribution network becomes an active network of double or multi terminal, compared to the previous single source radial network. This kind of change not only limits the flexibility of power grid operation, but also reduces the stability of power grid operation.

\section{The Characteristics of Relay Protection on Distribution Network in China}

The traditional distribution network is a single source radiation network (In order to ensure the reliability of power supply, the hand pull ring or two side power supply is used.) ,which is based on the high voltage transmission line, the power station and the power distribution line to reach the user. In China, $10 \mathrm{kV}$ distribution network protection is mainly three-stage current protection [1,2]. The main advantage of current protection is simple, economical and reliable, which has been widely used in the low-voltage power grid. After the distributed generation is connected to the distribution network, the operation mode of the distribution network is complicated and changeable, which makes it difficult to set the current protection of the original distribution network, sometimes simply cannot be set in accordance with the requirements of regulation, even cannot play a protective effect[3].

\section{Theoretical Analysis of the Influence of DG on Distribution Network original current Protection}

\subsection{Distributed generation is located at the adjacent feeder of the fault}

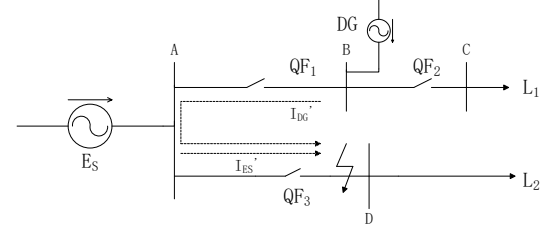

Fig.2-1 Distributed generation is located at the adjacent feeder of the fault point 
As shown in Figure 2- 1, Line L1 contains a distributed power supply (DG), If the line L2 occurs three-phase fault, DG provides a short-circuit current $\mathrm{I}_{\mathrm{DG}}^{\prime}$ to the point of failure via bus $\mathrm{A}$, The protection at the circuit breaker QF1 detects the reverse fault current $\mathrm{I}_{\mathrm{QF} 1}=\mathrm{I}_{\mathrm{DG}}^{\prime}$ provided by the DG.

The time-to-instantaneous trip current limit setting for QF1 and QF2 is[2]:

$$
\begin{gathered}
I_{\text {set-QF1 }}^{\mathrm{I}}=K_{\text {rel }}^{\mathrm{I}} \cdot I_{K \cdot \max }=\frac{E_{S}}{Z_{S}+Z_{1}} \\
I_{\text {set QPF }}^{\mathrm{I}}=K_{\text {rel }}^{\mathrm{I}} \cdot I_{K \cdot 2 \cdot \max }=\frac{E_{S}}{Z_{S}+Z_{1}+Z_{2}} \\
I_{Q F 1}=\frac{E_{S}}{\frac{\left(Z_{D G}+Z_{1}\right) Z_{S}}{Z_{S}+Z_{1}+Z_{D G}}+\lambda Z_{3}} \times \frac{Z_{S}}{Z_{S}+Z_{1}+Z_{D G}}
\end{gathered}
$$

$\mathrm{Z}_{\mathrm{S}}$ is the equivalent impedance of the grid, $\mathrm{Z}_{1} 、 \mathrm{Z}_{2}$ 和 $\mathrm{Z}_{4}$ are the line impedance of $A B, B C$ and $\mathrm{AD}$, and $\mathrm{Z}_{\mathrm{DG}}$ is the equivalent impedance of the $\mathrm{DG}$ and the transformer.

If $\mathrm{E}_{\mathrm{S}}=1, \mathrm{Z}_{\mathrm{S}}=0.5, \mathrm{Z}_{1}=1.1, \mathrm{Z}_{2}=0.75, \mathrm{Z}_{4}=1.2$; Then $\mathrm{I}_{\text {set-QF1 }}^{\mathrm{I}}=0.75, \mathrm{I}_{\text {set } \mathrm{QF} 2}^{\mathrm{I}}=0.51$.

$$
\text { If } \begin{aligned}
\mathrm{x}_{\mathrm{DG}}^{\prime \prime}=0.25, \mathrm{~S}_{\mathrm{B}}=100 ; Z_{D G} & =x_{D G}^{\prime \prime} \frac{S_{B}}{S_{D G}}=\frac{25}{S_{D G}} \\
I_{Q F 1} & =\frac{0.5 S_{D G}}{(0.55+1.92 \lambda) S_{D G}+30 \lambda+12.5}
\end{aligned}
$$

The smaller the $\lambda$, the larger theI $\mathrm{QF1}_{1}$, when $S_{\mathrm{DG}}$ is known. As the different of the $S_{\mathrm{DG}}$, the closer the fault point is to the bus, the lager the short-circuit current, the protection more likely to malfunction, so take $\lambda=0.001$.

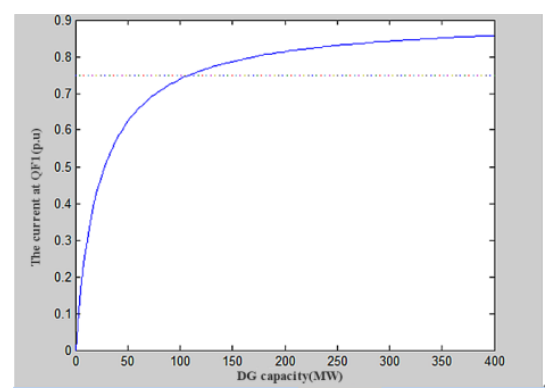

Fig.2-2 the fault current detected by QF1 in the short circuit of the adjacent lines changes with the capacity of DG

As shown in Figure 2-2, when the three-phase short-circuit fault occurs at the close position of the adjacent line bus, the protection of the line may be refused due to the action of DG. If the protection setting is exceeded, the action jumps QF1, resulting in line L1 Power interruption

\subsection{DG is located at the upper reaches of the fault point}

(1). DG access will reduce the protection of sensitivity (For example, $\mathrm{QF}_{1}$ in Figure 2-3)

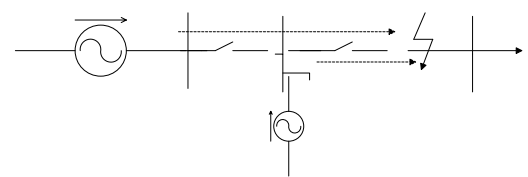

Fig.2-3 DG is located at the upper reaches of the fault point

As shown in Figure 2-3, the fault current $\mathrm{I}_{\mathrm{ES}}^{\prime}$ detected at $\mathrm{QF}_{1}$ is reduced when the line $\mathrm{BC}$ is short-circuited after the DG is connected compared with the original distribution network. As a result, the sensitivity of the protection is reduced, And even lead to the protection of refuse to move. Considering the two-phase short circuit, the protection over current protection setting at $\mathrm{QF}_{1}$ is set to 0.2 , I III $\mathrm{II} \cdot \mathrm{QF} 3=0.2$, Formula (6)can be obtained. Taking into account the impact of $\lambda$ on the sensitivity, $\lambda$ is lager, the lower the sensitivity, take $\lambda=1$, Formula (7) can be obtained. 


$$
\begin{gathered}
I_{Q F 1}=\frac{\sqrt{3}}{2} \times \frac{E_{S}}{\frac{\left(Z_{D G}+Z_{1}\right) Z_{S}}{Z_{D G}+Z_{1}+Z_{S}}+\lambda Z_{2}} \times \frac{Z_{D G}}{Z_{D G}+Z_{1}+Z_{S}} \\
I_{Q F 1}^{\prime}=\frac{25 \sqrt{3}}{3.5 S_{D G}+62.5}
\end{gathered}
$$

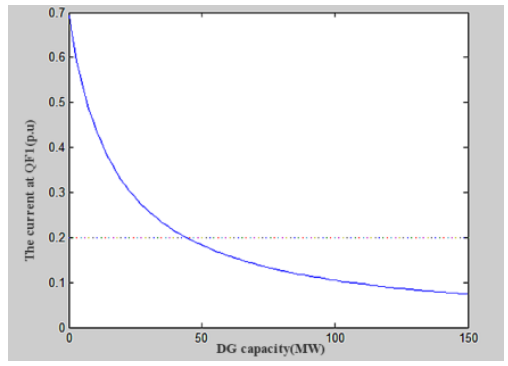

Fig.2-4 DG capacity change curve of fault current detected by $\mathrm{QF}_{1}$ at the end of two phase short circuit at BC

As shown in Figure 2-4, when the DG short-circuit capacity exceeds $44 \mathrm{~mW}$, the fault current at $\mathrm{QF}_{1}$ is less than its over-current setting. If $\mathrm{QF}_{2}$ of the quick-break protection action at this time, $\mathrm{QF}_{1}$ will refuse to move, the fault cannot be isolated.

(2). DG access will cause the protective device to malfunction (For example, $\mathrm{QF}_{2}$ in Figure 2-3)

The system short-circuit current $\mathrm{I}_{\mathrm{ES}}^{\prime}$ and the short-circuit current $\mathrm{I}_{\mathrm{DG}}^{\prime}$ of the DG constitute the protection at $\mathrm{QF}_{2}$ detected fault current due to the $\mathrm{DG}$, when the fault occurs at the terminal feeder. The current $\mathrm{I}_{\mathrm{QF} 2}^{\prime}$ detected by the protection $\mathrm{QF}_{2}$ increases, and the larger $\mathrm{I}_{\mathrm{QF} 2}^{\prime}$ is, $\mathrm{I}_{\mathrm{QF} 2}^{\prime}$ is likely to be larger than the current setting value of the protection section, resulting in protection malfunction.

Protects the fault current detected by $\mathrm{QF}_{2}$ is Formula (8): With the above parameters, the formula 9 can be obtained[4]:

$$
\begin{aligned}
I_{Q F 2}^{\prime}= & \frac{E_{S}}{\frac{\left(Z_{S}+Z_{1}\right) Z_{D G}}{Z_{S}+Z_{1}+Z_{D G}}+Z_{2}} \\
I_{Q F 2}^{\prime} & =\frac{1.6 S_{D G}+25}{1.2 S_{D G}+58.75}
\end{aligned}
$$

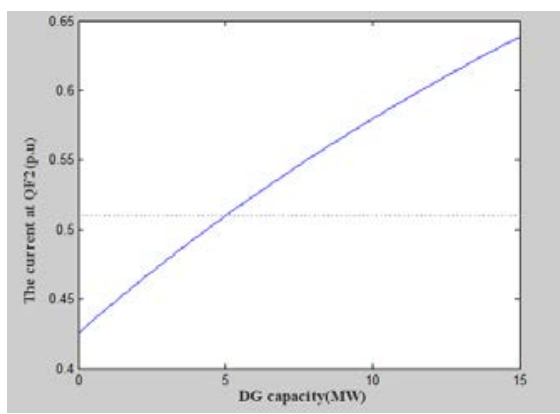

Fig.2-5 DG capacity change curve of fault current detected by QF2 at the end of short circuit of BC

From Figure 2-5, when the three-phase short circuit occurs at the end of the BC line, when the DG capacity is greater than 5MW,the fault current detected by the protection at QF2 will be larger than its quick-break protection setting value, may causing malfunction.

3.3 DG is located in the downstream of the fault point

(1). There is no protection between the DG and fault point 


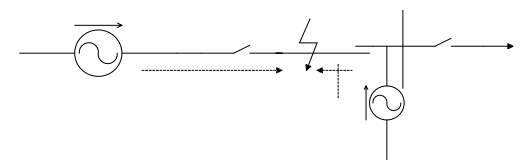

Fig. 2-6 DG is located in the downstream of the fault point and no protection between the DG and fault point

As shown in Figure 2-6, if the DG is installed near the substation, there is no protection between the DG and the fault point. Although both DG and system provide short circuit current to the fault point, the current through $\mathrm{QF}_{1}$ is the system short-circuits currentI $\mathrm{I}_{\mathrm{ES}}^{\prime}$, which is independent of the DG access. Therefore, the protection behavior is not affected[3,4].

(2).DG is installed on the terminal line

FIG.2-7 DG is located at the downstream of the fault point and is protected before the fault point.

As shown in Figure 2-7, if the DG is installed on the terminal line, the protection at QF2 detects the fault current $\mathrm{I}_{\mathrm{DG}}^{\prime}$ in the opposite direction provided by the DG. However, since the current protection does not have the ability to recognize the current direction, when the fault current exceeds the protection value, the protection device will operate.

\section{Simulation of the influence of DG on distribution network current protection}

The schematic of the grid is shown in Figure 3-1:

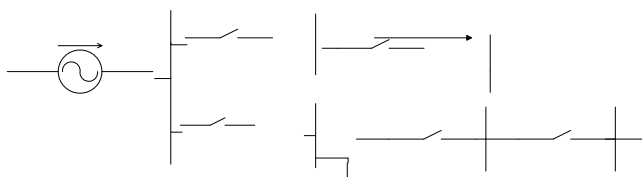

Fig.3-1 Schematic diagram of distribution network with distributed generation

Distribution network selection $10 \mathrm{KV}$ distribution network, the reference capacity of $10.5 \mathrm{KV}$, the system is not grounded neutral point way. The active load power is $2 \mathrm{MW}$, the reactive power is $0.4 \mathrm{Mvar}$, the positive sequence impedance of the overhead line is $0.442+\mathrm{j} 0.35$, the zero sequence impedance is $0.5197+\mathrm{j} 1.63$. Instead of the DG, the Wind turbine generator is connected to the bus $\mathrm{D}$ by the transformer.

The line lengths are: $A B=5 K M ; B C=5 K M ; A D=10 K M ; D E=4 K M ; E F=4 K M$;

In the MATLAB simulation software, the distribution network simulation model is set up as follows [7]:

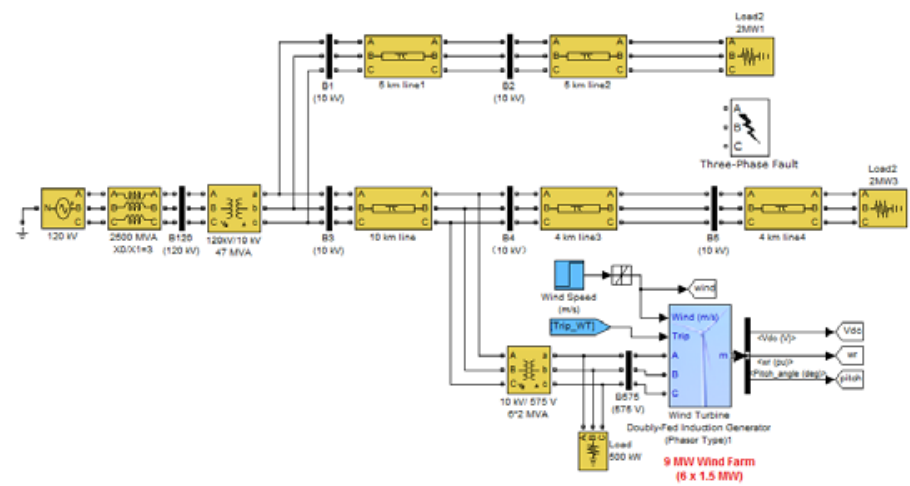

Fig.3-2 Simulation diagram of distribution network with distributed generation 
DG is not connected to the distribution network and there is no fault, the normal operation of the current measured at each point as follows:

$\mathrm{I}_{\mathrm{QF} 1}=\mathrm{I}_{\mathrm{QF} 2}=144 \mathrm{~A} ; \mathrm{I}_{\mathrm{QF} 3}=\mathrm{I}_{\mathrm{QF} 4}=\mathrm{I}_{\mathrm{QF5}}=155 \mathrm{~A}$;

Three-stage current protection settings and sensitivity are shown in Table 1:

Table 1: Three-stage current protection settings and sensitivity

\begin{tabular}{|c|c|c|c|c|c|c|}
\hline \multicolumn{2}{|c|}{ protection } & $\mathrm{QF}_{1}$ & $\mathrm{QF}_{2}$ & $\mathrm{QF}_{3}$ & $\mathrm{QF}_{4}$ & $\mathrm{QF}_{5}$ \\
\hline \multirow{2}{*}{$\begin{array}{c}\text { Setting } \\
\text { value(A) }\end{array}$} & $\mathrm{I}$ & 2622 & 1523 & 1522 & 1138 & 138 \\
\cline { 2 - 7 } & II & 1577 & $/$ & 915 & 684 & 684 \\
\cline { 2 - 7 } & III & 217 & 217 & 202 & 202 & 202 \\
\hline \multirow{2}{*}{$\begin{array}{c}\text { Time } \\
\text { Limit(S) }\end{array}$} & II & 0.5 & $/$ & 1.2 & 0.6 & $/$ \\
\cline { 2 - 7 } Sensitivity & III & 1 & 0.5 & 1.5 & 1.5 & 0.5 \\
\hline
\end{tabular}

When the three-phase short-circuit fault occurs at the end of the DE line, the current changes at $\mathrm{QF}_{4}$ as the DG short-circuit capacity changes as shown in Table 2 below:

Table 2 current changes at $\mathrm{QF}_{4}$ as the DG short-circuit capacity changes

\begin{tabular}{|c|c|c|c|c|c|}
\hline DG short-circuit capacity(MW) & 1.5 & 3.0 & 4.5 & 6 & 7.5 \\
\hline Protection $\mathrm{QF}_{4}$ Measured current value(KA) & 1.5 & 1.99 & 2.07 & 2.15 & 2.23 \\
\hline
\end{tabular}

When three-phase short-circuit fault occurred at the end of the line DE, DG short-circuit capacity is 7.5MVA, the protection $\mathrm{QF}_{4}$ measured current value is $2.23 \mathrm{KA}$, which has exceeded the protection of $\mathrm{QF}_{4}$ current quick-break protection setting value. Therefore, when the short circuit fault occurs near the outlet of the $\mathrm{DE}$ circuit, the protection $\mathrm{QF}_{4}$ and $\mathrm{QF}_{5}$ may operate, and the selectivity cannot be guaranteed.

\section{Conclusion}

The model is established by MATLAB simulation software, and the effect of distributed power access is analyzed by changing the injection capacity value of DG. Compared with the previous theoretical results, its main effect is to increase the current effect by the DG. At the same time, the DG capacity also affects the protection action of the distribution network. When the DG capacity is large, in order to avoid the adverse effect, the current protection setting can be checked in advance. If necessary, can also be considered for the current protection of the direction of additional components, is conducive to DG in the power system in the promotion and application.

\section{References}

[1]. Zhang Baohui, Yin Xianggen. Power system relay protection [M]. Beijing: China Electric Power Press, 2005.

[2]. Dong Xinzhou, Chen Xingying. Distribution fault location and power restoration [M]. Beijing: China Electric Power Press, 2012.

[3]. Guo Ming ,Ai Qian .Analysis on the influence of connecting distributed generation on the relaying of distribution system[J]. Distribution \& Utilization, 2010, 27 (1): 1-37.

[4]. Cao Jingliang. Study of the Impact of DG on the Protection of Distribution Network [D].Wuhan: Huazhong University of Science and Technology, 2008.

[5]. Research on the impact of DG capacity on the distribution network current protection and countermeasure[J].Power System Protection and Control, 2010,38(22):156-165.

[6]. Lu Yuping. A study on effect of dispersed generator capacity on power system protection [C].Power Engineer Society General Society. USA: IEEE, 2007:1-6.

[7]. Qun Yu, NA Cao. Modeling and Simulation of Power System in MATLAB /Simulink [M]. Beijing: Mechanical Industry Press, 2011. 